\title{
COMPARATIVE STUDY OF DIFFERENT FORMULAE OF ULTRASONOGRAPHIC QUANTIFICATION OF THE AMOUNT OF PLEURAL EFFUSION
}

\author{
By
Mohamed Sabri Ahmed Amin, Abo-Bakr Helal Al-Asmar and Houssam El-Din Hassanin Abd El-Naby \\ Department of Chest, Faculty of medicine, Al-Azhar University, Cairo, Egypt \\ Corresponding author: Mohamed Sabri Ahmed Amin, Mobile: (+20)01016427899, \\ E-mail: mohamed.sabri.1992@gmail.com
}

\begin{abstract}
Background: Pleural effusion may be a result of a primary pulmonary illness. It also can be the pleural manifestation of numerous of diseases that primarily affect other organs. Quantification of pleural effusion is of great value in clinical practice, as it usually guides the plan of management. Chest ultrasound (U/S) is one of the helpful non-invasive means in estimating pleural fluid volume.

Objective: To correlate the U/S estimated volumes of pleural fluid calculated by studied formulae, with the actual effusion volume, and to identify the most accurate formula in quantifying the pleural fluid volume.

Patients and Methods: This prospective cross-sectional study was carried out in the department of Chest, Bab Al-sha'reia University Hospital, during the period from October 2019 to September 2020, and included forty patients with clinical and radiological diagnosis of pleural effusion. Ultrasound estimation of the amount of pleural effusion was done using 4 different formulae, followed by full pleural drainage through either simple aspiration or tube thoracostomy. Lastly, the ultrasonographically estimated fluid volumes were then compared to the actually drained fluid volume.

Results: The supine formulae showed excellent correlation with the drained pleural fluid volume, with Pearson correlation coefficient $(\mathrm{r})=0.9607$ and 0.9602 for Eibenberger and Balik formulae respectively (pvalue $<0.0001)$. On the other side, the erect formulae were found to have reasonable correlations with the drained volume, with $r=0.4017(\mathrm{p}$-value $=0.0102)$ and $0.5729(\mathrm{p}$-value $<0.0001)$ for Goecke1 and Goecke 2 respectively. All studied formulae failed to quantify the pleural effusion volume accurately when comparing its estimated volume to the actually drained fluid volume.
\end{abstract}

Conclusion: The 4 studied formulae had good correlations with the actually drained volume. However, supine formulae were better than erect formulae.

Key words: Pleural effusion; Ultrasonographic; Quantification.

\section{INTRODUCTION}

Approximately 1-10 $\mathrm{mL}$ of fluid are normally present in the pleural space, maintained by the balance between the hydrostatic and oncotic forces in the visceral and parietal pleural vessels and extensive lymphatic drainage (Light, 2013).

The use of ultrasonography (U/S) in examining the pleural space has become a standard practice worldwide (Mercer et al., 2017). Physicians show a rising 
interest about examining the pleural space using U/S, which has a positive impact on patient's overall care, as there are many advantages of U/S over other radiological investigations (Lichtenstein, 2017).

Ultrasonographically, pleural effusion volume can be estimated quantitatively or qualitatively. Qualitative estimations classify effusion as minimal, moderate or massive, while a quantitative approach involves the use of various formulae (Cerquitella et al., 2016).

Many ultrasound-based formulae were put for pleural effusion volume estimation, but the ideal one should be simple, accurate and easily performed (Ibitoye et al., 2018).

The present work aimed to correlate the U/S estimated volumes of pleural fluid calculated by studied formulae, with the actual effusion volume.

\section{PATIENTS AND METHODS}

This prospective cross-sectional study was carried out at Chest Department, AlAzhar University Hospitals, Cairo, Egypt, during the period from October 2019 to September 2020. It included forty patients diagnosed clinically and radiologically as pleural effusion.

\section{Exclusion Criteria:}

Patients with any of the following were totally excluded from the study; loculated/encysted effusions or empyema, very small effusions $(<10 \mathrm{~mm}$ pleural separation by fluid on ultrasonography), inability to accommodate supine or full erect positions, thoracic deformities, diseases affecting diaphragmatic motility directly or indirectly, previous thoracic surgery, known bleeding tendency disorder, regular anti-coagulation or patients with international normalization ratio (INR) >2or platelets count $<100000 / \mathrm{mm}^{3} \quad$ (Müller et al., 2015),conditions interfering with good U/S window, e.g. subcutaneous emphysema, chest wall edema and morbid obesity and lastly those with incomplete fluid drainage on post-thoracentesis ultrasonography ( $>5 \mathrm{~mm}$ separation of the pleural layers).

Ethical clearance was granted by AlAzhar Faculty of Medicine Ethics and Research Committee. Informed consents were obtained from all participants.

All subjects were submitted to the following; full history taking, thorough clinical examination, routine laboratory investigations (complete blood count, random blood sugar, liver function tests, kidney function tests and coagulation profile), plain chest X-ray (posteroanterior and lateral views), CT chest with or without IV contrast (if needed), chest $\mathrm{U} / \mathrm{S}$ and complete thoracentesis.

\section{Chest U/S:}

The curvilinear transducer $(2-6 \mathrm{MHz})$ of the ultrasound machine model (SonoScape - SS1 China) was used in the study. Ultrasonographic examination was first done while the patient is completely supine to obtain values (in millimeters) for the supine formulae. The chest was examined at the laterodorsal/ posterolateral part of the chest wall through the intercostal spaces. The transducer was oriented perpendicularly to the chest wall (sharp transverse scan). Measurements were taken at maximum inspiration, while the patient holding his/her breathe. The maximum perpendicular (interpleural) distance 
between the posterior surface of the lung and the posterior chest wall was recorded (Ibitoye et al., 2018).

Patient sat in a fully erect position, and measurements (in centimeters) were taken for the erect formulae. The chest was examined at the laterodorsal/ posterolateral part of the chest wall through the intercostal spaces, with the transducer oriented longitudinally along the long axis of the chest. The craniocaudal extent (lateral height) of the effusion and the lung base to middiaphragm distance were measured at the end of expiration (Ibitoye et al., 2018).

Each measurement was repeated for 3 times and the average value was obtained for statistical analysis. The estimated effusion volume was subsequently calculated for each studied formula as follows:

\section{Supine Formulae:}

\section{- Eibenberger: $\mathrm{EV}=\mathbf{4 7 . 6 X - 8 3 7}$}

Where $\mathrm{EV}=$ estimated effusion volume $(\mathrm{mL}), \quad \mathrm{X}=$ maximum perpendicular distance between the pulmonary surface and the chest wall at maximal inspiration (mm) with the probe in the transverse position (Mathis, 2011).

\section{- Balik: $E V=20 X$}

Where $\mathrm{EV}=$ estimated effusion volume $(\mathrm{mL}), \quad \mathrm{X}=$ maximum perpendicular distance between the pulmonary surface and chest wall at maximal inspiration ( $\mathrm{mm})$ with the probe in transverse position (Mathis, 2011).

\section{Erect Formulae:}

\section{- Goecke 1: $\mathrm{EV}=90 \mathrm{X}$}

Where $\mathrm{EV}=$ estimated effusion volume $(\mathrm{mL}), \mathrm{X}=$ craniocaudal extent of the effusion at the dorsolateral chest wall measured in erect position $(\mathrm{cm})$ with the probe oriented longitudinally (Mathis, 2011).

\section{- Goecke 2: $\mathrm{EV}=70(\mathrm{X}+\mathrm{LDD})$}

Where $E V=$ estimated effusion volume (mL), $X=$ craniocaudal extent of the effusion at the dorsolateral chest wall measured in the erect position $(\mathrm{cm})$, $\mathrm{LDD}=$ lung base to mid-diaphragm distance (subpulmonary height of the effusion) $(\mathrm{cm})$, with the probe oriented longitudinally (Mathis, 2011).

Thoracocentesis was then performed under ultrasound guidance, either through simple aspiration, or via insertion of a 28Fr chest tube (Polymed, Argyle, India) into the mid-axillary line through the fourth or fifth intercostal spaces and connected to underwater seal drainage system. Total lung expansion and complete drainage was confirmed by plain chest radiography and U/S.

\section{Statistical analysis:}

Data were collected, coded, revised, verified and computerized. Statistical analysis of data was performed using Statistical Package for the Social Sciences (SPSS) version 15 (IBM, Corp, Chicago, IL, USA). Quantitative data were expressed as range, mean \pm standard deviation (SD), while qualitative data were expressed as frequency and percentage.

P-values $\leq 0.05$ were considered significant. Kruskalwallis test was used to 
compare two or more groups and to study whether samples originate from the same distribution or not. While Pearson
Correlation Coefficient tests (r) was used to study the degrees of correlation.

\section{RESULTS}

Forty patients were included in this study. The ages of patients ranged from 28 to 86 years old, with a mean age of $58.9 \pm$ 13.4 years. Among the study population $57.5 \%$ were males and $42.5 \%$ were females. In $60 \%$ of the patients the pleural effusion was right-sided, while in $40 \%$ the pleural effusion was left-sided.

Dyspnea was the most predominant symptom, it existed in $95 \%$ of all patients, $62.5 \%$ were suffering from chest pain, $50 \%$ had cough, $20 \%$ gave history of toxic symptoms and only $5 \%$ were presented by both hemoptysis and pressure manifestations due to huge mediastinal mass.

When assessing co-morbidities among the study population, hypertension was the most frequent co-morbidity, being existed in $27.5 \%$. Diabetes mellitus, ischemic heart disease and chronic obstructive pulmonary disease (COPD) equally occupied the second rank with $17.5 \%$ for each, chronic kidney disease came after and presented in $10 \%$ and lastly chronic liver disease in $7.5 \%$ of patients.

The supine formulae calculated results showed excellent (very high) correlations with the drained pleural fluid volume, with $r=0.9607$ and 0.9602 for Eibenberger and Balik formulae respectively ( $\mathrm{p}$-value $<0.0001$ ). On the other side, the erect formulae estimated volumes were found to have reasonable (good) correlations with the drained volume, with $\mathrm{r}=0.4017(\mathrm{p}$-value $=0.0102)$ and 0.5729 (p-value $<0.0001)$ for Goecke1 and Goecke 2 respectively (Table 1).

Table (1): Correlations of estimated pleural fluid volumes calculated by studied formulaewith the actually drained fluid volume

\begin{tabular}{|c|c|c|}
\hline Correlations & $(\mathbf{r})$ & p-value \\
\hline Formulae & $\mathbf{0 . 9 6 0 7}$ & $<\mathbf{0 . 0 0 0 1}$ \\
\hline Eibenberger vs Actual & $\mathbf{0 . 9 6 0 2}$ & $<\mathbf{0 . 0 0 0 1}$ \\
\hline Balikvs Actual & $\mathbf{0 . 4 0 1 7}$ & $\mathbf{0 . 0 1 0 2}$ \\
\hline Goecke 1 vs Actual & $\mathbf{0 . 5 7 2 9}$ & $<\mathbf{0 . 0 0 0 1}$ \\
\hline
\end{tabular}

(r): Pearson Correlation Coefficient, vs: versus.

The mean estimated pleural fluid volumes by the supine formulae were $2190.8 \pm 860.4$ and $1273.2 \pm 360.8 \mathrm{~mL}$ for Eibenberger and Balik respectively, while those calculated using the erect formulae were $1066.8 \pm 304.2$ and $1371.4 \pm 350.6$ $\mathrm{mL}$ for Goecke1 and Goecke 2 respectively. There were statistically significant differences ( $p$-values $<0.0001$ ) between all the means calculated by the formulae in one hand and the mean of actually drained pleural fluid volume $(2322.5 \pm 867.9 \mathrm{~mL})$ in the other hand (Table 2). 
Table (2): Comparison of the estimated pleural fluid volumes calculated by studied formulaewith the actually drained fluid volume

\begin{tabular}{|c|c|c|c|c|c|c|c|}
\hline Formula & $\begin{array}{c}\text { Actual } \\
(\mathrm{N}=40)\end{array}$ & $\begin{array}{c}\text { Goecke1 } \\
(\mathrm{N}=40)\end{array}$ & $\begin{array}{c}\text { Goecke2 } \\
(\mathrm{N}=40)\end{array}$ & $\begin{array}{c}\text { Balik } \\
(\mathrm{N}=40)\end{array}$ & $\begin{array}{c}\text { Eibenberger } \\
(\mathrm{N}=40)\end{array}$ & $\mathrm{KW}$ & $\begin{array}{c}\mathrm{P}- \\
\text { value }\end{array}$ \\
\cline { 1 - 7 } Mean & 2322.5 & 591.9 & 928.7 & 1273.2 & 2190.8 & \multirow{2}{*}{134.3} & $<0.001$ \\
\hline$\pm \mathrm{SD}$ & 867.9 & 168.3 & 220.9 & 360.8 & 860.4 & \\
\hline
\end{tabular}

KW: Kruskal Wallis Test.

\section{DISCUSSION}

Many authors developed sonographic methods for the volumetric quantification of pleural effusions in either supine or erect positions (Teichgräber and Hackbarth, 2018).

The current work studied the accuracy of four of these methods in comparison to the actually drained volume. These 4 formulae were chosen for evaluation because they can be performed easily and quickly, making them helpful in routine clinical applications (Mathis, 2011).

The findings we get coincide with the strong correlation between Eibenberger and Balik formulae in one hand and the actually drained pleural fluid volume in the other hand obtained by Vetrugno and Bove (Vetrugno and Bove, 2018).

On the other side, these results oppose those obtained by a recent study, in which the erect formulae were more correlated with the drained volume (Ibitoye et al., 2018). Despite that, in the same study Balik and Eibenberger equations showed good correlation with the actually drained fluid volume.

The correlation coefficients of the supine formulae reported in the current study are higher than that recorded by the study of (Usta et al., 2010), which included patients with post-operative pleural effusion secondary to cardiac surgery, and depended on a different modified equation $(\mathrm{V}=16 \mathrm{D})$, in which $(\mathrm{V})$ is the totally drained pleural fluid volume and (D) is the maximum distance between lung base and the centre of the diaphragm while patient in supine position.

A rough method of quantification was followed, and effusions were classified into small, moderate and large according to the number of intercostal spaces (ICSs) at which the effusion could be detected by the U/S probe starting from the costophrenic angle; small (one ICS), moderate (2-3 ICS) and large ( $\geq 4$ ICSs). Small effusions were $<500 \mathrm{~mL}$, moderate effusions 500-1000 mL and large effusions $>1000 \mathrm{~mL}$ (Brockelsby et al., 2016).

Ibitoye et al., (2018) reported that Eibenberger formula the most accurate of the 4 studied formulae in predicting the volume of pleural effusion, with a nonsignificant difference between the volume of fluid calculated using Eibenberger formula and the actually drained fluid volume. Pleural fluid volumes calculated by other formulae showed a statistically significant under-estimation when compared with the truely drained volume.

In contrary to the current study, Mathis, (2011) reported an observation about considerable underestimation of the volume calculated using Eibenberger formula in relation to the real volume, 
especially in those with large thoracic cavities. Other limitations of Eibenberger formula include diaphragmatic elevation and the effect of the lung parenchymal status on the shape of the pleural fluid, i.e. poorly aerated/collapsed lower lobe will mostly displace underlying pleural fluid, thus yielding a smaller estimated volume than the actual volume.

Our results mismatch with those of a previous compartive study included 5 equations; (Goecke 1, Goecke 2 and Balik), in addition to another 2 equations; one of them is that moduled by Usta et al. (2010), and the last one is a modification of Goecke 1 formula by replacing the factor 90 by 100 rendering it $\mathrm{EV}=100 \mathrm{X}$. This study concluded that Goecke 2 equation is the most accurate in estimating the volume of pleural fluid among the studied equations, with an intra-class correlation coefficient (ICC) equals 0.83 , while the modified Goecke 1 formula $(\mathrm{EV}=100 \mathrm{X})$ is the simplest to calculate, with a nearby ICC (0.79). However, this disparity between their results and ours may be attributed to differences in the measurement landmarks used to derive sonographic estimates (Hassan et al., 2017).

\section{CONCLUSION}

All studied formulae showed good correlations with the actually drained volume, but supine formulae were the best to do that.

\section{REFERENCES}

1. Brockelsby $C$, Ahmed $M$ and Gautam $M$ (2016): Pleural disease assessment and outcome (Pleural effusion size estimation: U/S, CXR or CT? Thorax; 3: A1-A288.

2. Cerquitella M, Saccomandi $P$, Schena E, Silvestri S, Scarlata S and Giua R (2016):
Ultrasound estimation of pleural effusion in geriatric patients. In: IEEE International Symposium on Medical Measurements and Applications (MeMeA), 15-18.

3. Hassan M, Rizk R, Essam $H$ and Abouelnour A (2017): Validation of equations for pleural effusion volume estimation by ultrasonography. J Ultrasound, 20: 267-271.

4. Ibitoye BO, IdowuBM, Ogunrombi AB and Afolabi BI (2018): Ultrasonographic quantification of pleural effusion: comparison of four formulae. Ultrasonography; 37(3): 254260.

5. Lichtenstein D (2017): Novel approaches to ultrasonography of the lung and pleural space: where are we now? Breathe; 13: 100-111.

6. Light RW (2013): Pleural diseases. 6th ed.Pbl.Philadelphia, PA: Lippincott Williams \&Wilkins., 126-129.

7. Mathis G (2011): Pleura. In: Mathis G, ed. Chest sonography. 3rd ed. Pbl.Heidelberg: Springer-Verlag., 30-32.

8. Mercer RM, Psallidas I and Rahman NM (2017): Ultrasound in the management of pleural disease. Expert Rev Respir Med.; 11: 323-331.

9. Müller MC,Arbous MS and Spoelstra-de Man (2015): Transfusion of fresh-frozen plasma in critically ill patients with a coagulopathy before invasive procedures: a randomized clinical trial (CME). Transfusion, 55(1): 26-35.

10. Teichgräber UK and Hackbarth J (2018): Sonographic bedside quantification of pleural effusion compared to compute tomography volumetry in ICU patients. Ultrasound Int Open, 4(4): E131-E135.

11. Usta E, Mustafi $M$ and Ziemer $G$ (2010): Ultrasound estimation of volume of postoperative pleural effusion in cardiac surgery patients. Interact CariovascThorac Surg.; 10: 204-207.

12. Vetrugno $L$ and Bove $T$ (2018): Lung ultrasound estimation of pleural effusion fluid and the importance of patient position. Ann. Intensive Care; 8: 125. 
در اسة مقارنة لمختلف معادلات القياس الكمى لمقدار الانصباب البللورى باستخدام الموجات فوق الصوتية محمد صبري أحمد أمين, أبو بكر هلال الأسمر, حسام الدين حسنين عبدالنبي قسم الأمراض الصدرية, كلية الطب, جامعة الأزهر, القاهرة

E-mail: mohamed.sabri.1992@gmail.com

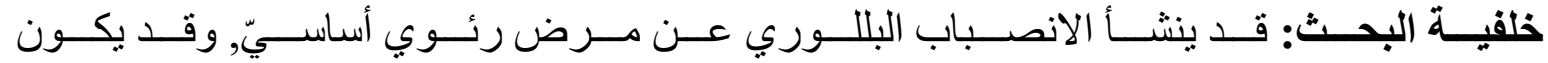

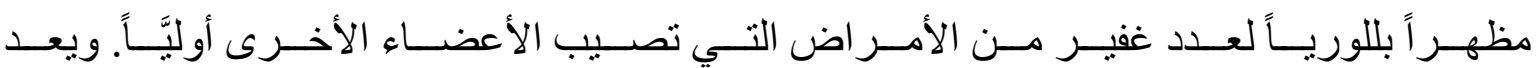

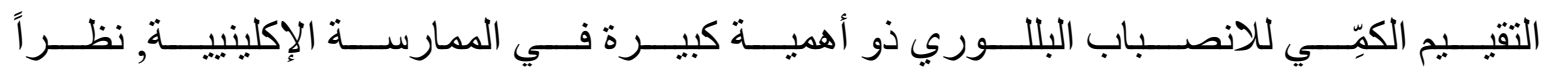

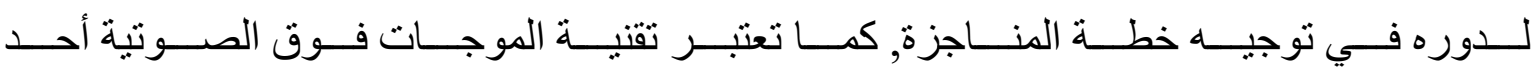
الوسائل المجدية غير الباضعة لتحقيق ذلك.

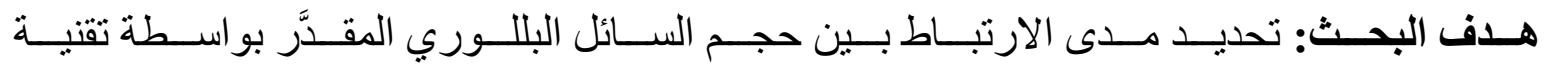

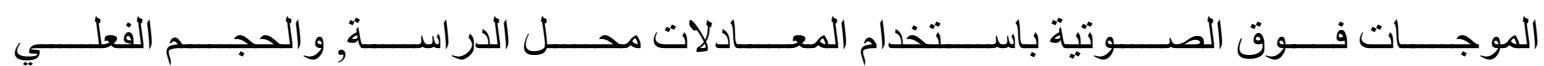

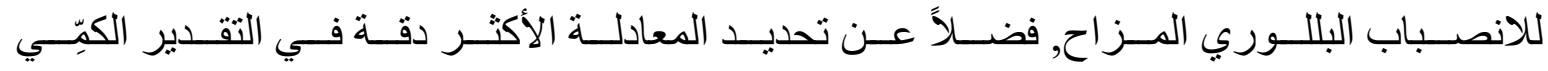
لحجم السائل البللوري.

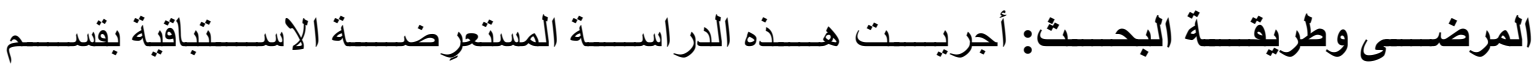

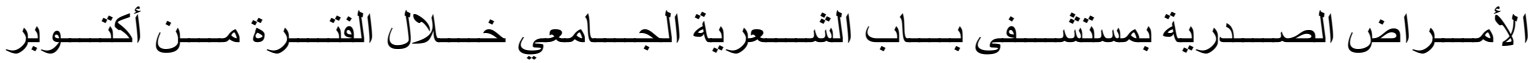

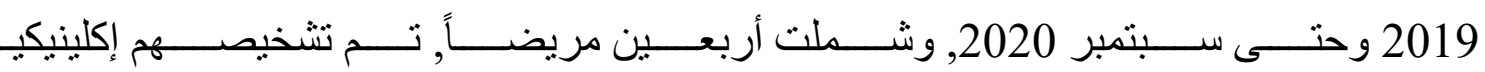

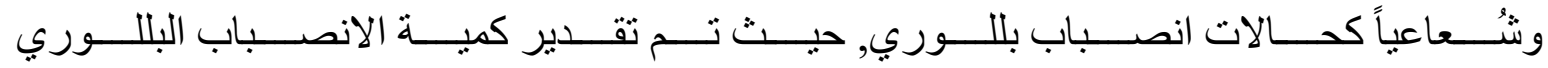

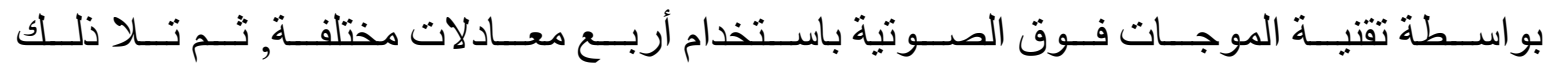

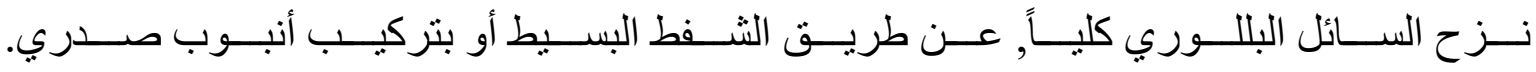

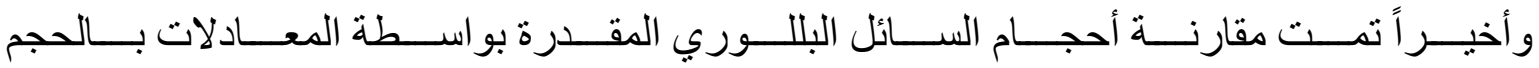
المز اح فعليًَا.

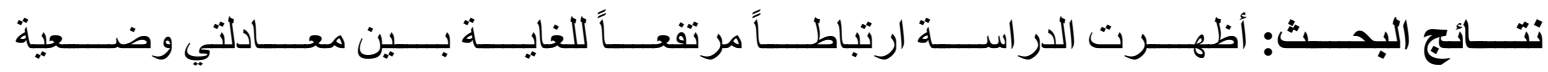

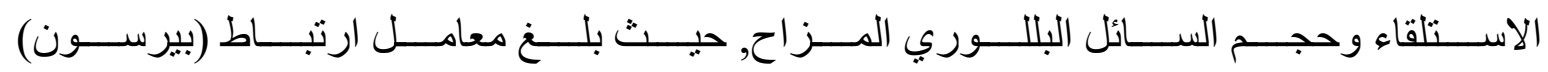

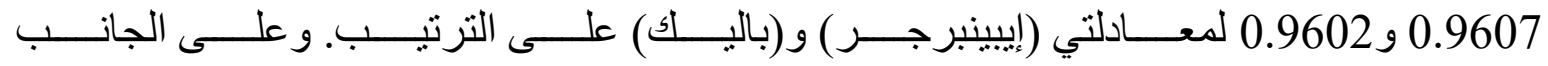

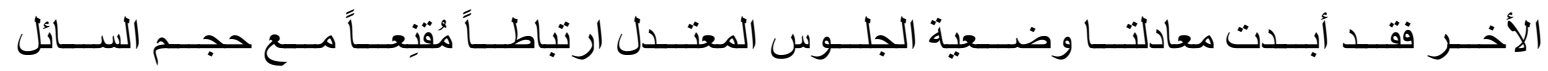




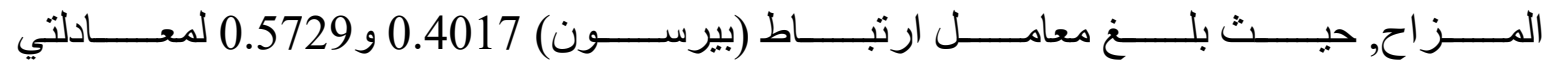

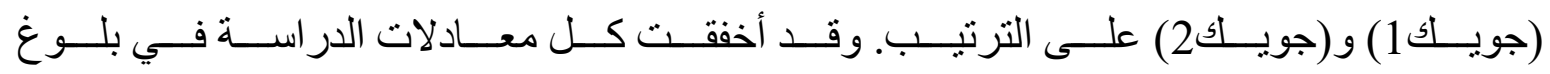

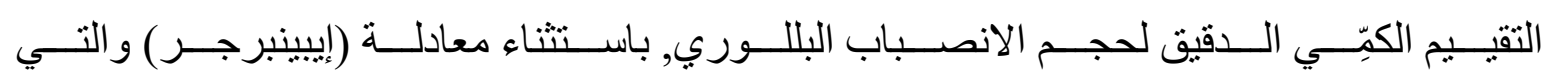

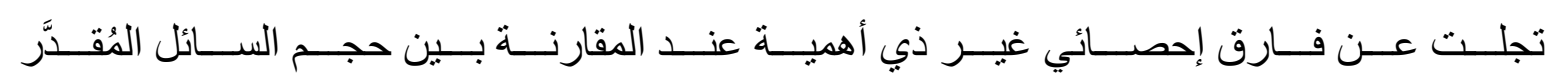

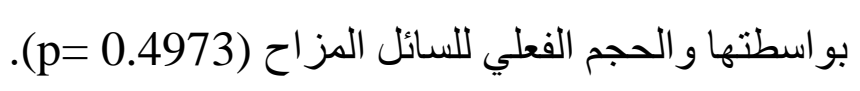

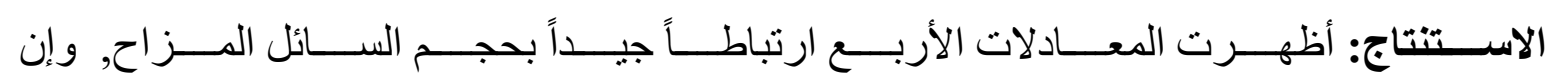

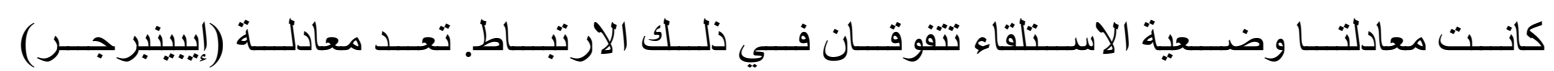
المعادلة الأمثل في التقدير الكمِّي لحجم السائل البللوري. الكلمات الدالة: الانصباب البللورى, الموجات فوق الصوتية, التقدير الكمى. 